Research

\title{
Actions to align energy projects with the Sustainable Development Goals
}

\author{
Constança Martins Leite de Almeida ${ }^{1}$ Elin Bergqvist ${ }^{1} \cdot$ Scott Thacker $^{2,3} \cdot$ Francesco Fuso Nerini $^{1,4}$
}

Received: 16 December 2020 / Accepted: 25 February 2021

(C) The Author(s) 2021 OPEN

\begin{abstract}
The 2030 Agenda is an aspiring set of goals and targets that aims to prompt humanity towards a sustainable development by 2030. In order to achieve this, actions that mitigate trade-offs and enhance synergies within the Sustainable Development Goals (SDGs) need to be identified. However, for the energy sector these actions are dispersed across the scientific literature, which is a clear barrier to encourage practitioners to have a proactive and pragmatic approach towards the SDGs. For this reason, a set of actions for energy projects was compiled. This compilation addresses the synergies and trade-offs identified in the Sustainable Development Goals Impact Assessment Framework for Energy Projects (SDG-IAE). One case of application was used to test the actions, the lighthouse Project VARGA. Subsequently, an analysis was conducted to understand how possible actions can impact different technologies, project stages, actors and SDG targets. In this way, enabling policymakers and project developers to define areas of action when evaluating policies or considering specific interventions. This article aims to be the starting point of stakeholder discussions that consistently frame energy projects within the achievement of the SDGs.
\end{abstract}

\section{Introduction}

In 2015, during the United Nations (UN) summit, heads of state and governments established the Agenda 2030. The Agenda consists of 17 Sustainable Development Goals (SDGs) with 169 targets. The SDGs focus on stimulating action for people, planet, prosperity, peace and partnerships [1]. All of these components have an integrated and interlinked nature that is of vital importance to ensure the purpose of the Agenda [1]. For this reason, an integrated implementation of the SDGs that captures the interactions between the different SDGs and sectors is needed $[2,3]$.

Since the establishment of the 2030 Agenda, research work has been conducted to map energy [4-6], infrastructures [7, 8], climate action [9], water [10], ecosystem services [11], oceans [12], mining [13] and artificial intelligence [14] to the SDGs. This included the identification of synergy and trade-offs and a call for action for specific sectors and SDGs. In the energy sector, different methods and frameworks were developed in order to identify $[15,16]$ and assess [17] different energy sources that contribute to the achievement of the SDGs. In energy systems, actions were identified as required to achieve 113 SDG targets [2]. This shows the complexity of energy systems and enables researchers and decision makers to better design specific policies and support actions that prompt the energy sector towards the SDGs.

Supplementary Information The online version contains supplementary material available at https://doi.org/10.1007/s43621-021-00020-3.

Constança Martins Leite de Almeida, cmlda@kth.se; $₫$ Francesco Fuso Nerini, francesco.fusonerini@energy.kth.se| ${ }^{1}$ School of Industrial Engineering and Management, KTH Royal Institute of Technology, SE-100 44 Stockholm, Sweden. ${ }^{2}$ United Nations Office for Project Services (UNOPS), Marmorvej 51, Copenhagen, Denmark. ${ }^{3}$ Environmental Change Institute, University of Oxford, South Parks Road, Oxford OX1 3QY, UK. ${ }^{4}$ Payne Institute for Public Policy, Colorado School of Mines, Golden, CO 80401, USA. 
To aid the achievement of the SDGs, the research community has been developing several tools to allow policymakers and project developers to understand how different SDGs interact and how their attainment can be impacted [18-23]. This includes the identification of possible actions to achieve specific SDGs [18-20] and the visualisation of possible connections between the SDGs and the climate goals [21]. In 2017, the United Nations, GSMA and Project Everyone developed the "SDGs in action" mobile app, where actions can be proposed or consulted in order to aid the achievement of a specific SDG target [18]. The United Nations Global Compact also developed a compilation of links from important initiatives and resources, in order to aid companies to advance in the direction of the SDGs [19]. In 2019, the United Nations Office for Project Services (UNOPS) and the University of Oxford-led Infrastructure Transition Research Consortium (ITRC) developed a tool, "sustainABLE", that provides actions to aid practitioners to achieve the SDGs within infrastructure projects [20].

With the aim of identifying the numerous linkages, either synergies or trade-offs, between the SDGs and energy projects [17] developed the Sustainable Development Goals Impact Assessment framework for Energy projects (SDG-IAE). The SDG-IAE provides possible linkages with the outcome targets, upon the completion of a questionnaire. In their work, it was identified a potential for synergies with 94 SDG targets and trade-offs with 58 SDG targets [17]. However, their study stopped at the identification of those linkages, without focusing on actions to limit the trade-offs and enhance the synergies. At present, to the best of the authors' knowledge, possible actions that project developers and policymakers, in the energy sector, can implement to mitigate trade-offs and enhance synergies within the SDGs, are disperse across the literature. This is a barrier to support energy practitioners to have a proactive and pragmatic approach towards Agenda 2030. Therefore, the authors intend to fill in the existent gap by proposing a new Framework, the Sustainable Development Goals Impact Assessment Framework for Energy Projects and Actions (SDG-IAEA) Framework, and corresponding Excel tool, that includes a sizeable compilation of actions. These actions address the linkages identified in the SDG-IAE. This will allow practitioners to enhance/mitigate the synergies/trade-offs of their energy projects and define priority areas when evaluating policies or considering specific interventions. In this way, a set of actions will be provided to the users, taking into consideration the specifications of their projects: primary energy source, technical specifications, project stage, level of development of the country and the actor that will implement the actions.

\section{Methods}

Figure 1 shows a graphical representation of the steps taken to develop this study and achieve the SDG-IAEA Framework.

As a first step, the definition of an action was adopted as "to do something to deal with a particular problem or matter" [24]. Then the research boundaries were defined to delimitate the content of the literature study. The actors, the project stages and the energy sources were determined, these included two actors, policymaker and project developer; three project stages, planning, building and operation; and seven energy sources, hydropower, wind power, solar power,

(a)

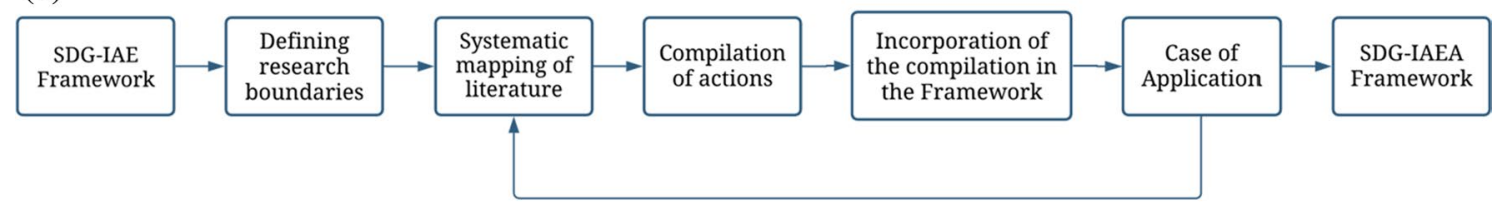

(b)

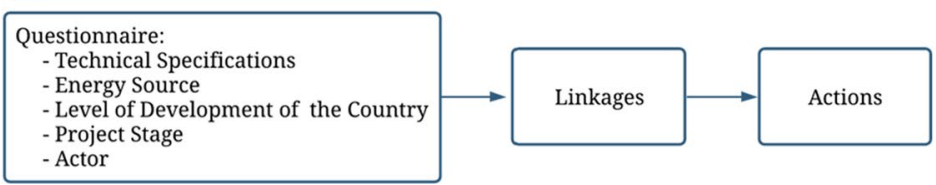

Fig. 1 SDG-IAEA Framework. a Workflow used to develop this study and achieve the SDG-IAEA. b Structure of the SDG-IAEA Framework: questionnaire regarding the technical specifications of the project, the energy source, the level of development of the country, the project stage and the actor; identification of the linkages, synergies and trade-offs, with the SDG targets based on the information of the questionnaire; selection of actions to present to the user based on the linkages, project stage and actor 
biomass/biofuels, waste to energy, nuclear and fossil fuels. The boundaries defined for each actor, stage and energy source can be found in electronic supplementary material: Annex A.

To assess each linkage, synergies or trade-offs, identified by [6], a systematic mapping of literature [25, 26] was conducted in order to answer two questions: (i) How can a policymaker or a project developer mitigate each of the identified trade-offs?; and (ii) How can a policymaker or a project developer enhance each of the identified synergies? The method used was adapted from previous studies evaluating SDGs linkages $[4,9,14]$. In order to map the studies, the linkages were divided in twenty-one topics and 47 subtopics (Table 1 in electronic supplementary material: Annex B). Each topic and subtopic were defined as a research criterion in combination with the following keywords: measures, actions, best practices, recommendations, guidelines and reports. When linkages only applied to a certain technology, the energy source was also included as a research criterion. For the material collection, Google scholar search was used to find and select literature published in academic journals, and it was aided by Google search for finding and assessing grey literature. As grey literature reports by international organizations, national and subnational agencies were considered.

To screen relevant papers and reports, an iterative process was created, an author was allocated to review actions for a certain linkage, which was then peer-reviewed by another author. This enabled additional points of view and considerations to arise. Afterwards in order to assemble the compilation of actions, the formulation of each action was developed, and allocated to one or more stages, technologies, actors and SDG targets. A schematic representation of this process for a sample action can be seen in Fig. 2 .

After the completion of the systematic mapping, the compilation of actions (electronic supplementary material: Annex B) was included in the existing SDG-IAE Framework and corresponding Excel tool. In this way the SDG-IAEA Framework was created. The actions in the SDG-IAEA Framework are actor, stage and technology specific, even though several apply to different actors, stages and technologies. As a proof of concept, to test and exemplify possible outputs of the SDGIAEA Framework the VARGA project was selected. The data for the VARGA project was gathered through several emails' conversations and interviews with the project manager of VARGA. The SDG-IAEA questionnaire was filled in twice for two different technologies, biomass/biofuels and waste to energy (electronic supplementary material: Annex C). This was done to take into consideration the power plant output, biogas, and the source of primary energy, sludge [27]. These results were discussed with the project manager during an interview (electronic supplementary material: Annex D).

After the case of application was conducted, changes were made to accommodate for issues and questions flagged during the first implementation of the Framework. This included reviewing more references and refining the formulation of some actions. Before the analysis of the results was conducted, the actions present in electronic supplementary material: Annex B were reorganised by action goal. The reasoning behind this was to understand which actions had the same goal but were in different topics/subtopics tables or framed differently. For example, the action "Plan/promote off grid and mini grid systems" can be found in two topics: "expansion of energy access" and "high cost of electricity". After this reorganisation, the 471 actions present in electronic supplementary material: Annex B, were reduced to 283 actions. Subsequently to better understand the complex and interlinked nature of the actions, and as part of the systematic

Fig. 2 Formulation of an action. The right $y$-axis shows the SDG targets that the action will make an impact on; the left $y$-axis represents the technologies for which an action can be applied; the lower $\mathrm{x}$-axis represents the project timeline by stage; the colour of the circle indicates which actor or actors take part in the action. ' $*$ ' represents an example of an action performed by a project developer for a hydropower plant in the planning stage

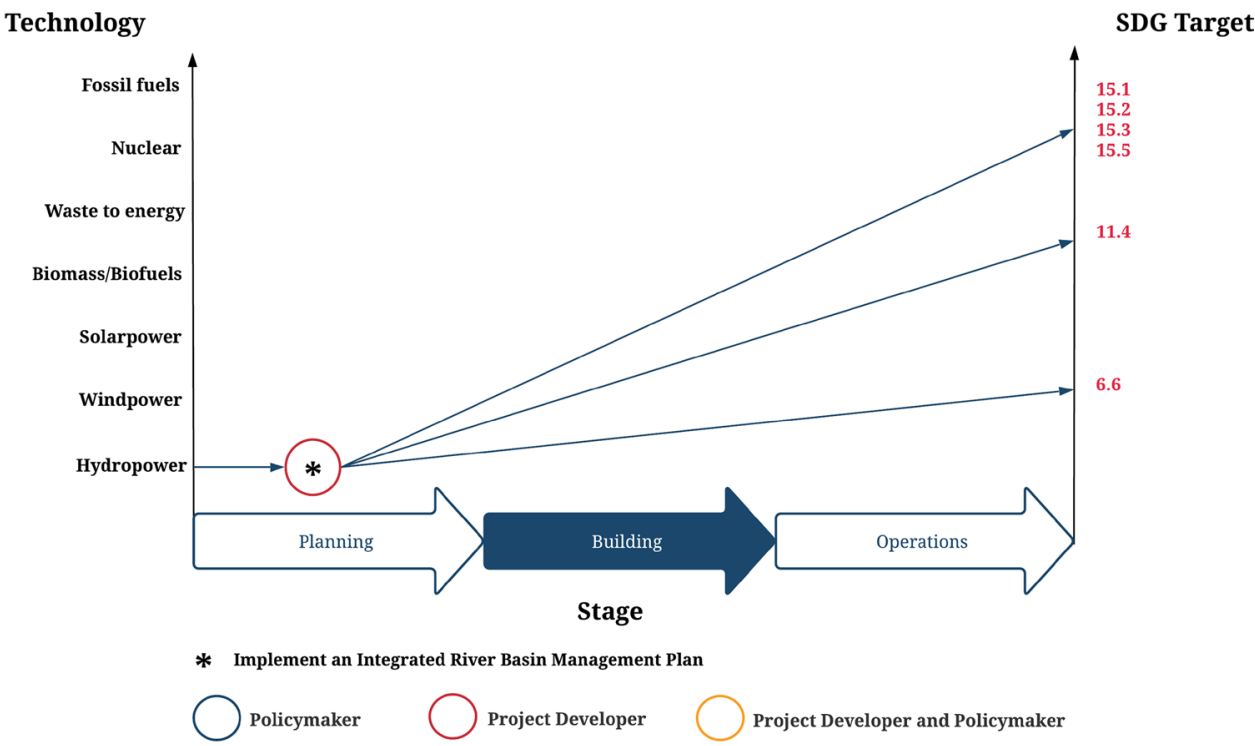


mapping $[25,26]$, simple numerical accounts of frequencies were performed to identify correlations and trends. This step focused on the frequency distribution of the 283 actions. The distributions were base on five parameters: SDG, number of SDG targets, technologies, stages and actors. The conclusions were synthetized in bar plots presented in Sect. 3.

\section{Actions}

\subsection{Overview of the identified actions}

This section provides an overview of the actions present in the Framework by focusing on the frequency distribution of five different parameters: SDGs, SDG targets, technologies, stages and actors. This includes 17 SDGs, 98 SDG targets, seven technologies, three stages and two actors.

A general overview of the 283 actions included in the compilation of actions is presented in Fig. 3, where the number of actions and linkages is specified by SDG. It can be observed that SDG4 (Quality Education) has the lowest number of linkages and the lowest number of actions. However, the number of actions is not always correlated with the number of linkages. For instance, SDG11(Sustainable Cities and Communities) has the highest number of actions, but it does not have the highest number of linkages. While, SDG12 (Sustainable Consumption and Production) has the highest number of linkages and a relatively low amount of actions. For both SDG4 and SDG17 (Partnerships for the Goals) it can be seen that the number of actions is identical to the number of linkages. Because, several linkages were aggregated into the same subtopics and, as a result, have the same set of actions. For example, in SDG4, out of the eight linkages identified, seven can be found in the subtopic "expansion of energy access synergies". Which results in a relatively low amount of actions compared to the linkages. This shows that different linkages can be very similar, and therefore be in the same subtopics and have the same proposed actions, even though, they impact different SDG targets.

In Fig. 4 it can be seen that actions can impact a wide amount of SDG targets, ranging from one to 52 SDG targets, with an average of six SDG targets impacted per action. In the compilation, eight actions are able to impact 42 or more SDG targets and 22 actions only have the possibility to influence one SDG target. Therefore, Fig. 4 shows that $92 \%$ of all actions impact more than one SDG target, which demonstrates the interlinked nature of actions addressing the SDGs. The actions impacting only one SDG target are mainly actions addressing linkages with SDG3 (Good Health and Well-being) and SDG6 (Clean Water and Sanitation), present in the subtopics "Large bodies of standing water" and "Withdrawal of water", which address SDG targets 3.3 and 6.2, respectively. On the other hand, all the seven actions impacting more than 42 SDGs targets, can be found under the subtopic "expansion of energy access synergies". This shows that the number of linkages and SDG targets an action can impact highly depends on the action topic and subtopic.

Fig. 3 Actions and linkages organised by SDG

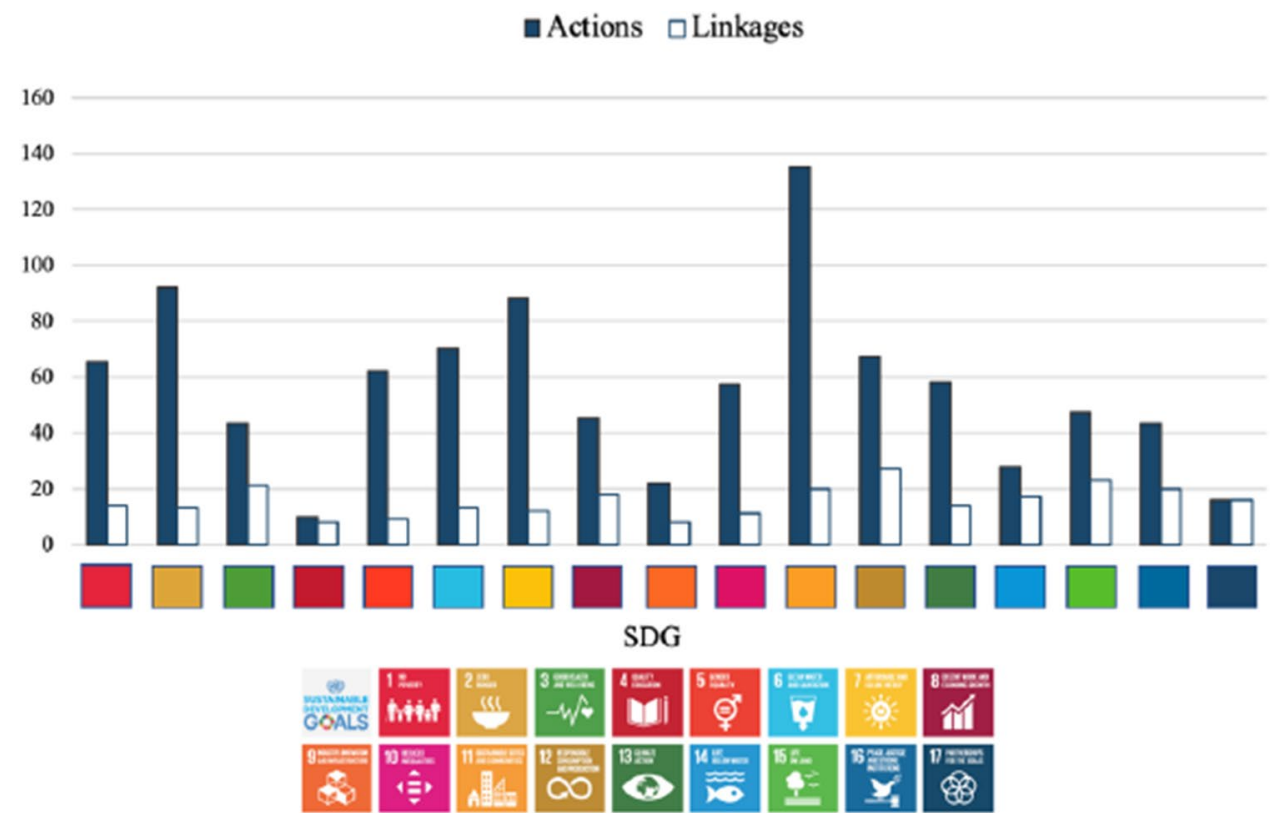




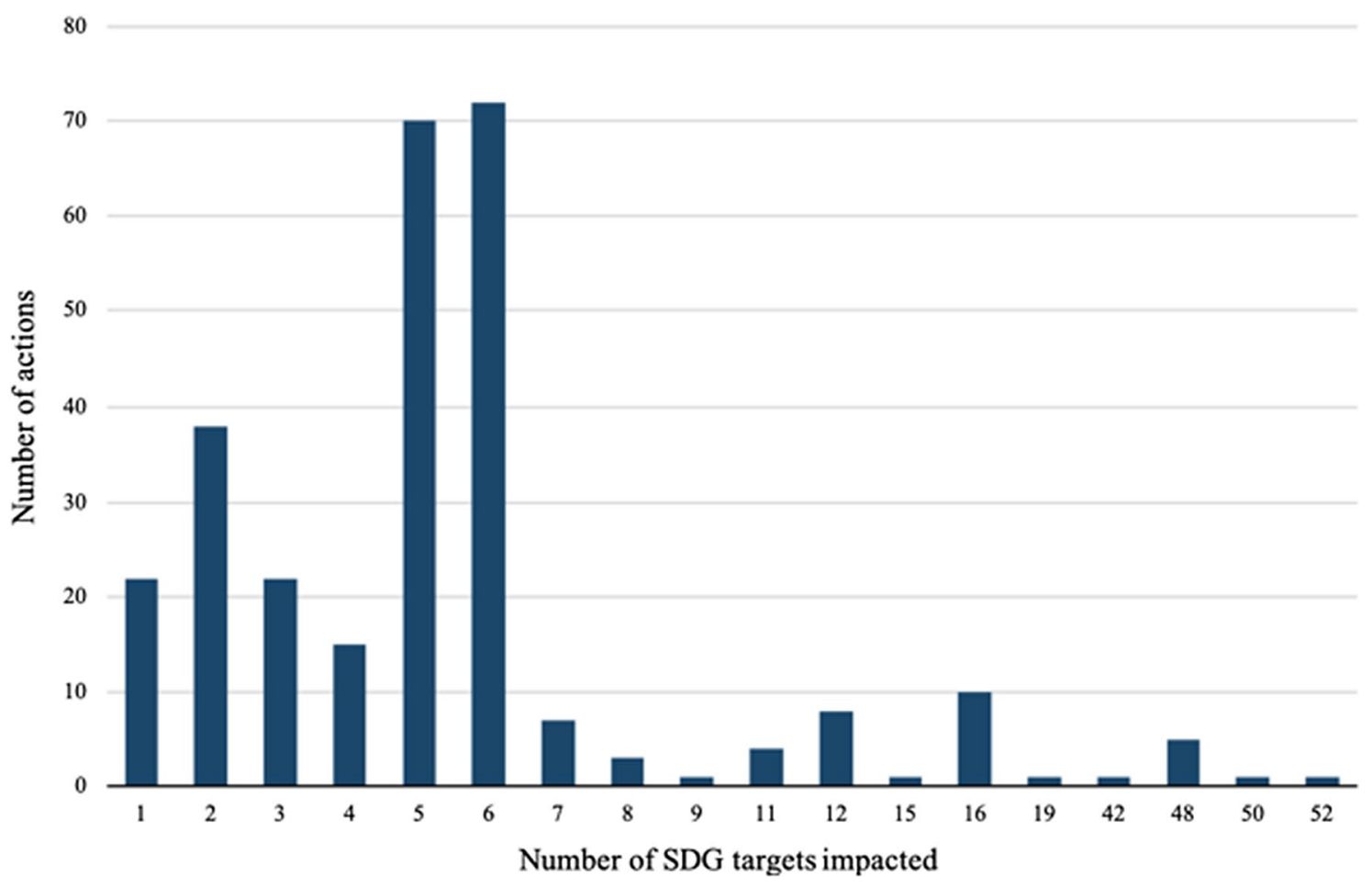

Fig. 4 Actions divided by the number of SDG Targets they impact

In order to identify the actions represented in Fig. 4 that have the widest impact among the SDG targets a list of areas where actions can influence more than 15 SDG targets was created. This can be seen in Table 1 and accounts for 20 different actions distributed in five areas. Even though each of these actions impact a high number of SDG targets, there is no quantification on the intensity of a possible impact. Therefore, Table 1 was designed to give an insight to both policymakers and project developers on actions that can impact the largest number of SDG targets in energy projects. In this way, Table 1 provides a preliminary view on possible impactful measures and areas of intervention that practitioners can implement in energy projects. However, stakeholders are encouraged to use the complete SDG-IAEA Framework to define possible priorities when evaluating specific projects.

From the 20 actions addressed in Table 1 all of them are applicable to more than four different technologies, with the majority being relevant to all the seven energy sources. This shows that actions that impact a high number of SDGs targets, will most likely be applicable to several technologies. As seen in Fig. 5a, $56 \%$ of all actions are applicable to all the energy sources and $37 \%$ are only applicable to one energy source. Actions that can be applied to more than one technology but not to all, two to six, are mainly actions regarding renewable energy sources and technologies that contribute to air pollution. For the actions only applicable to one specific technology, 30\% refer to biomass/biofuel projects, due to the fact that 15 linkages solely target this type of energy source. These actions address the use and selection of crops for the production of energy, and possible conflicts and impacts that may arise from it.

Table 1 Areas with a large numbers of SDG targets impacted

\section{Areas}

Education and awareness regarding renewable energy solutions, energy poverty, threats to the world cultural and natural heritage, and spreading of diseases

Reduce water consumption within power plants: recycle water, change cooling systems and use partially or fully degraded water sources

Expansion of energy access: increase grid connections; promote off grid, mini grid systems and decentralised energy solutions; implement storage capacity to reduce intermittency; build knowledge about different types of local available energy sources, through the use of a Geospatial Information System (GIS); and provide digital payment methods

Robust financial support for energy projects

Stakeholder engagement 
(a)

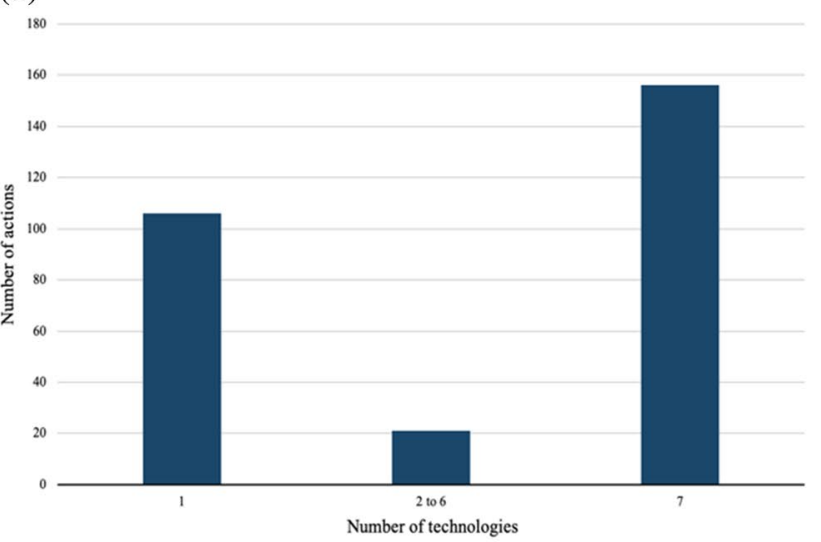

(b)

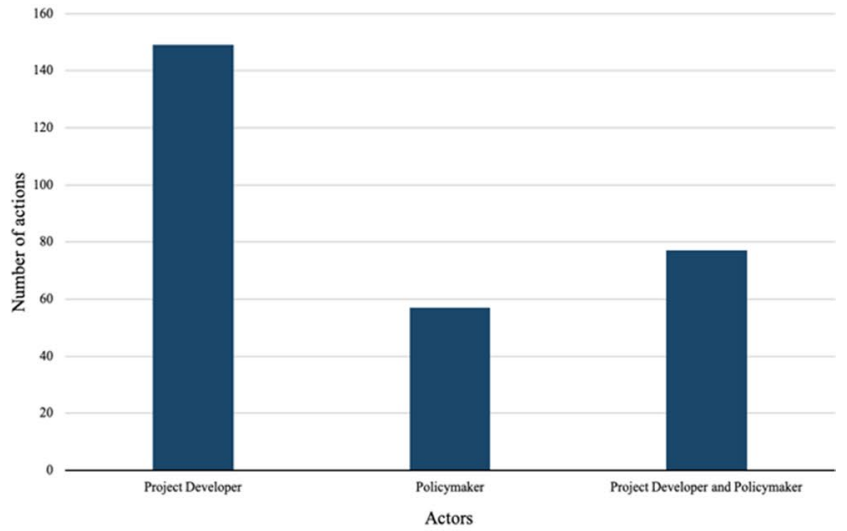

(c) 160

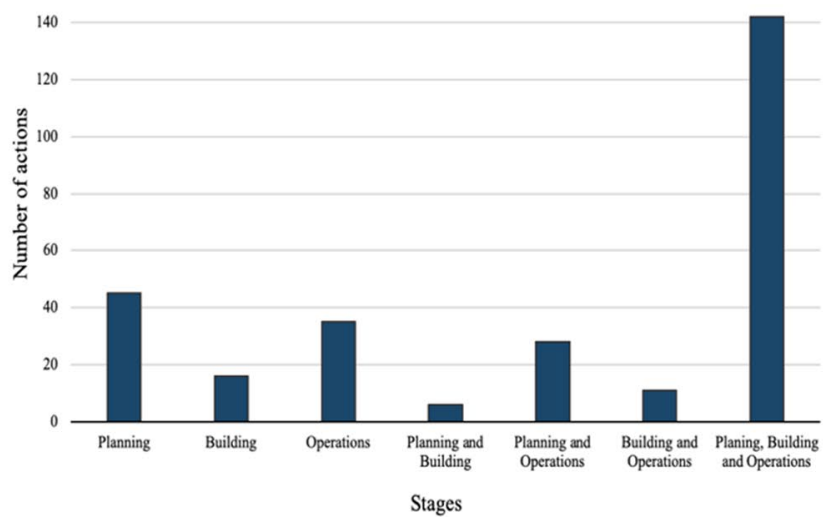

Fig. 5 Overview of the actions present in the Framework. The actions were divided by: a Number of Technologies, b Actors and c Stages

In Fig. 5 it can be observed that the majority of the actions apply to three stages, seven technologies and one actor, project developer. However, this does not mean that the majority of the actions apply to these stages, technologies and actor simultaneously. Actions applicable to project developers are predominantly stage and technology specific, with $87 \%$ of technology specific actions and $76 \%$ of stage specific actions being proposed for only project developers. These actions can mainly be found in the planning and operation stage of a project. Actions only allocated in the planning stage tend to prevent possible trade-offs and actions only allocated in the operation stage tend to focus on mitigation of the existent trade-offs. Therefore, the most crucial phase of a project is the planning stage, since the implementation of actions in this stage can avoid future trade-offs with the SDGs in the following stages. Actions that apply to all the stages and technologies are predominantly proposed to both actors. These actions on average impact a high number of SDG targets. Another dimension present in the Framework is the existence of actions only proposed for developing countries. Which account for 12 actions and addresses several linkages with SDG 17, regarding economic development, financial aid, and capacity building.

\subsection{Case of application}

As a proof of concept to test and exemplify possible outputs of the SDG-IAEA Framework, the VARGA Project was selected. The VARGA Project is located at the Avedøre Wastewater Treatment Plant, Denmark (WWTP) [27]. This project will transform the WWTP into a waste resource recovery facility (WRRF), which will create biogas, through anaerobic digestion, and biological fertiliser from both sludge and source-sorted organic waste [27].

As explained in the methodology section, the SDG-IAEA Framework was filled in twice, with the data provided by VARGA's project manager, for both biomass/biofuels and waste to energy (electronic supplementary material: Annex C). While filling in the questionnaire, it was understood that there is a risk of bias, from the Framework user. Which can significantly alter the linkages and actions proposed. To mitigate this risk, the Framework should be filled in by different 
stakeholders, ideally in a workshop setting, to ensure that several perspectives are taken into consideration. After the analysis of the Framework's results, several linkages were dismissed using the built-in user defined priority function. This feature allows users to rank the different linkages on a scale from 0 (Not Applicable) to 5 (Top Priority). Forty-three synergies and 13 trade-offs were identified as applicable to the project, with linkages regarding incineration, biomass production through agriculture and provision of clean cooking fuels being classified as " $0=$ Not Applicable".

The aim of the VARGA project is to incorporate the notion of circular economy through the utilisation of nutrients and the production of energy from urban waste and wastewater. The project has six main characteristics that differentiate it from others: optimised carbon harvesting, minimisation of nitrous oxide, valuation chain of organic waste, recycling phosphorus and nitrogen nutrients, release of raw materials, and source optimisation of organic waste biopulp in anaerobic digestion and upgrading of biogas [27]. Therefore, the most important synergy of this project is the increase of energy, water and natural resource efficiency. The two most relevant trade-offs are the vulnerability extreme weather events, and the disturbance of marine ecosystems.

The area where the plant is located may be under the threat of climate change and extreme weather events, which has trade-offs with SDG7 (Affordable and Clean Energy) and SDG13 (Climate Action) [28]. To limit this, the actions in Table 2 were proposed [29-31]. During the meeting with the project manager, it was understood that possible tradeoffs associated with extreme weather events were already analysed. The actions proposed in the Framework to mitigate these trade-offs were already implemented in the project. A climate risk assessment and a 100-year simulation of sea level rise were conducted for the WWTP (electronic supplementary material: Annex D).

The project has another relevant trade-off regarding ecosystem disturbance. The release of wastewater, which have nutrients imbalances, to the aquatic system can lead to the disturbance of marine ecosystems [32, 33]. The actions suggested to mitigate this trade-off can be seen in Table 3. The recycling of phosphorus and nitrogen which in high concentration in wastewater can cause eutrophication $[32,33]$ will be ensured by the plant and the nutrients will be reused in the agriculture sector. This action mitigates the trade-offs [34,35] present in Table 3 and the synergies [36-39] presented in Table 4, since the recovery of nutrients is also a possible action to enhance the natural resource efficiency [40].

This project is considered a state-of-the-art project both in terms of water, energy and natural resources efficiency which influences SDG6 (Clean Water and Sanitation), SDG7, SDG8 (Decent work and Economic Growth), SDG9 (Industry, Innovation and Infrastructure), SDG12 (Responsible Consumption and Production) and SDG13 [36-39]. This is due to the implementation of highly efficient energy technologies, the recovery of nutrients from wastewaters and production of fertilisers [40].

\section{Conclusion}

This article presents a significant compilation of actions that allows project developers and policymakers, in energy projects, to mitigate their trade-offs and enhance their synergies within the SDGs. At the same time, it demonstrates the interlinkage nature of actions for the SDGs and highlights the need for three specific filters, technology, actor and stage, in order to navigate the compilation. This study can aid the identification of areas where actions can impact the highest number of SDGs. In this way, allowing both actors to evaluate policies or consider specific interventions within energy projects. During the process of applying the SDG-IAEA Framework to the case of application it was understood the potential value of the Framework for initial sustainability assessments and its capability, among others, to attract project finance.

Table 2 Actions to mitigate extreme weather events in the VARGA project

\begin{tabular}{llll}
\hline Trade-offs & Proposed action & Stage & Actor \\
\hline 7.1, 13.1 & Conduct a risk assessment and management plan & Planning & Project developer \\
& Monitor climate change impacts & Building, operation & Policymaker, project developer \\
& Prepare an emergency plan & Planning, building, operation & Project developer \\
& Implement flood protection measures & Planning, building, operation & Project developer \\
& Analyse if decentralised power production is feasible & Planning & Policymaker, project developer \\
& and if it reduces risks & &
\end{tabular}




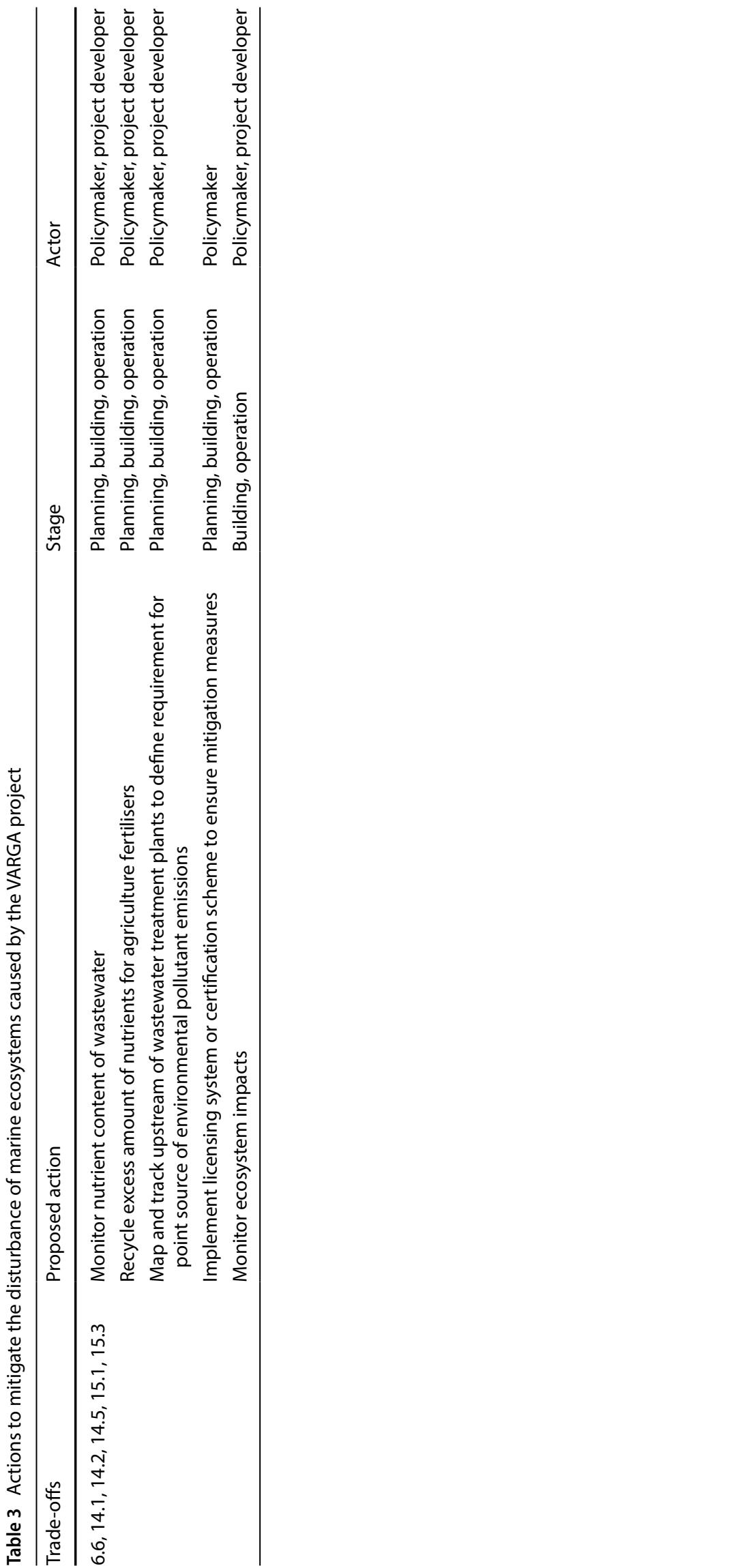


Table 4 Actions to enhance the water, energy and natural resource efficiency of VARGA

\begin{tabular}{llll}
\hline Synergies & Proposed action & Stage & Actor \\
\hline $6.4,7.3,8.4,9.4,12.1,12.2,13.2$ & Use energy efficient technologies & Planning, building, operation & Policymaker, project developer \\
& Analyse all sources of tradable resources & Planning, building, operation & Policymaker, project developer \\
& Provide funding to scale up innovations & Planning, building, operation & Policymaker, project developer \\
& Recover heat & Planning, operation & Policymaker, project developer \\
& Recover nutrients & Planning, operation & Policymaker, project developer \\
& Use an energy management system & Operation & Project developer \\
\hline
\end{tabular}

The compilation of actions and corresponding version of the SDGs-IAEA Framework Excel based tool is designed to be improved upon future work, as it is applied to a wider variety of energy projects. The Excel based tool is available on GitHub, where practitioners can provide inputs and submit suggestions for improvements. This resource will be critical for collecting user feedback and make comprehensive updates as more projects are assessed using the Framework. In this way, this article and the corresponding SDGs-IAEA Framework excel based tool aim to be the starting point of stakeholder discussions that consistently frame energy projects within the achievement of the SDGs.

Future work might attempt to include more types of energy sources in order to cover a wider range of energy projects. A scaling option, taking into consideration the size of the project, could be evaluated as a filter to the linkages and actions, even though it poses some questions regarding the classification of the scale of the projects. The possibility of changing the programming language of the Framework and migrate it to an interactive website, where it could be available to everyone, might also be considered. In addition, the incorporation of this Framework with other tools that trace back SDGs could also be a future task.

Acknowledgements We would like to thank Nick Ahrensberg, the project manager of the VARGA project, for the data provided and the invaluable feedback and discussions throughout our work.

Authors' contributions All authors contributed to the study conception and design. Material preparation, data collection and analysis were performed by CMLA and EB. The first draft of the manuscript was written by CMLA and all authors commented on previous versions of the manuscript. All authors read and approved the final manuscript.

Funding Open access funding provided by Royal Institute of Technology. The research work for this article was funded by the Formas Grant No. 2018-01253.

Data availability Not applicable.

Code availability Not applicable.

Declarations

Competing interests The authors declare no competing interests.

Open Access This article is licensed under a Creative Commons Attribution 4.0 International License, which permits use, sharing, adaptation, distribution and reproduction in any medium or format, as long as you give appropriate credit to the original author(s) and the source, provide a link to the Creative Commons licence, and indicate if changes were made. The images or other third party material in this article are included in the article's Creative Commons licence, unless indicated otherwise in a credit line to the material. If material is not included in the article's Creative Commons licence and your intended use is not permitted by statutory regulation or exceeds the permitted use, you will need to obtain permission directly from the copyright holder. To view a copy of this licence, visit http://creativecommons.org/licenses/by/4.0/.

\section{References}

1. United Nations, 2017. Transforming our world: the 2030 agenda for sustainable development. In: A new era in global health. Springer Publishing Company, New York, NY. https://doi.org/10.1891/9780826190123.ap02.

2. Blanc DL. Towards integration at last? The sustainable development goals as a network of targets. Sustain Dev. 2015;23:176-87. https:// doi.org/10.1002/sd.1582.

3. Liu J, Hull V, Godfray HCJ, Tilman D, Gleick P, Hoff H, Pahl-Wostl C, Xu Z, Chung MG, Sun J, Li S. Nexus approaches to global sustainable development. Nat Sustain. 2018;1:466-76. https://doi.org/10.1038/s41893-018-0135-8. 
4. Fuso Nerini F, Tomei J, To LS, Bisaga I, Parikh P, Black M, Borrion A, Spataru C, Castán Broto V, Anandarajah G, Milligan B, Mulugetta Y. Mapping synergies and trade-offs between energy and the sustainable development goals. Nat Energy. 2018;3:10-5. https://doi.org/10. 1038/s41560-017-0036-5.

5. Santika WG, Anisuzzaman M, Bahri PA, Shafiullah GM, Rupf GV, Urmee T. From goals to joules: a quantitative approach of interlinkages between energy and the sustainable development goals. Energy Res Soc Sci. 2019;50:201-14. https://doi.org/10.1016/j.erss.2018.11.016.

6. McCollum DL, Echeverri LG, Busch S, Pachauri S, Parkinson S, Rogelj J, Krey V, Minx JC, Nilsson M, Stevance A-S, Riahi K. Connecting the sustainable development goals by their energy inter-linkages. Environ Res Lett. 2018;13:033006. https://doi.org/10.1088/1748-9326/ aaafe3.

7. Thacker S, Adshead D, Fay M, Hallegatte S, Harvey M, Meller H, O'Regan N, Rozenberg J, Watkins G, Hall JW. Infrastructure for sustainable development. Nat Sustain. 2019;2:324-31. https://doi.org/10.1038/s41893-019-0256-8.

8. Adshead D, Thacker S, Fuldauer L, Hall J. Delivering on the sustainable development goals through long-term infrastructure planning. Glob Environ Change. 2019;59:101975. https://doi.org/10.1016/j.gloenvcha.2019.101975.

9. Fuso Nerini F, Sovacool B, Hughes N, Cozzi L, Cosgrave E, Howells M, Tavoni M, Tomei J, Zerriffi H, Milligan B. Connecting climate action with other sustainable development goals. Nat Sustain. 2019;2:674-80. https://doi.org/10.1038/s41893-019-0334-y.

10. Velis $\mathrm{M}$, Conti KI, Biermann F. Groundwater and human development: synergies and trade-offs within the context of the sustainable development goals. Sustain Sci. 2017;12:1007-17. https://doi.org/10.1007/s11625-017-0490-9.

11. Wood SLR, Jones SK, Johnson JA, Brauman KA, Chaplin-Kramer R, Fremier A, Girvetz E, Gordon LJ, Kappel CV, Mandle L, Mulligan M, O'Farrell P, Smith WK, Willemen L, Zhang W, DeClerck FA. Distilling the role of ecosystem services in the sustainable development goals. Ecosyst Serv. 2018;29:70-82. https://doi.org/10.1016/j.ecoser.2017.10.010.

12. Singh GG, Cisneros-Montemayor AM, Swartz W, Cheung W, Guy JA, Kenny T-A, McOwen CJ, Asch R, Geffert JL, Wabnitz CCC, Sumaila R, Hanich Q, Ota Y. A rapid assessment of co-benefits and trade-offs among sustainable development goals. Mar Policy. 2018;93:223-31. https://doi.org/10.1016/j.marpol.2017.05.030.

13. United Nations, 2016. Mapping Mining to the Sustainable Development Goals: An Atlas.

14. Vinuesa R, Azizpour H, Leite I, Balaam M, Dignum V, Domisch S, Felländer A, Langhans SD, Tegmark M, Fuso Nerini F. The role of artificial intelligence in achieving the sustainable development goals. Nat Commun. 2020;11:233. https://doi.org/10.1038/s41467-019-14108-y.

15. Nilsson M, Lucas P, Yoshida T. Towards an integrated framework for SDGs: ultimate and enabling goals for the case of energy. Sustainability. 2013;5:4124-51. https://doi.org/10.3390/su5104124.

16. Büyüközkan G, Karabulut Y, Mukul E. A novel renewable energy selection model for United Nations' sustainable development goals. Energy. 2018;165:290-302. https://doi.org/10.1016/j.energy.2018.08.215.

17. Castor J, Bacha K, Nerini F. SDGs in action: a novel framework for assessing energy projects against the sustainable development goals. Energy Res Soc Sci. 2020;68:101556. https://doi.org/10.1016/j.erss.2020.101556.

18. SDGs in Action, 2020. https://sdgsinaction.com/. Accessed 26 Oct 2020.

19. United Nations Global Compact, 2020. How Your Company Can Advance Each of the SDGs | UN Global Compact. https://www.unglobalco mpact.org/sdgs/17-global-goals. Accessed 26 Oct 2020.

20. SustainABLE, 2019. https://sustainable.unops.org/\#/About. Accessed 26 Oct 2020.

21. NDC-SDG Connections, n.d. SEl. https://www.sei.org/projects-and-tools/tools/ndc-sdg-connections/. Accessed 25 Jan 2021.

22. SDG Synergies, n.d. https://www.sdgsynergies.org. Accessed 25 Jan 2021.

23. SDG Impact Assessment Tool, n.d. https://sdgimpactassessmenttool.org/about. Accessed 25 Jan 2021.

24. ACTION | meaning in the Cambridge English Dictionary, 2020 https://dictionary.cambridge.org/dictionary/english/action. Accessed 2 Nov 2020.

25. James KL, Randall NP, Haddaway NR. A methodology for systematic mapping in environmental sciences. Environ Evid. 2016;5:7. https:// doi.org/10.1186/s13750-016-0059-6.

26. An Introduction to Systematic Reviews, 2021. SAGE Publications Ltd. https://uk.sagepub.com/en-gb/eur/an-introduction-to-systematicreviews/book245742. Accessed 30 Jan 2021.

27. Project VARGA, 2020. About VARGA. https://projekt-varga.dk/en/about-varga/. Accessed 2 Nov 2020.

28. The World Energy Council, 2015. The road to resilience - managing and financing extreme weather risks.

29. Winne S, Horrocks L, Kent N, Miller K, Hoy C, Benzie M, \& Power R. 2012. Increasing the climate resilience of waste infrastructure. Final Report under Defra contract ERG 1102. AEA group, published by Defra. https://assets.publishing.service.gov.uk/government/uploads/ system/uploads/attachment_data/file/183933/climate-resilience-full.pdf. Accessed 02 May 2020.

30. International Atomic Energy Agency (IAEA), 2019. Adapting the energy sector to climate change. https://www-pub.iaea.org/MTCD/Publi cations/PDF/P1847_web.pdf. Accessed 2 May 2020.

31. European Environment Agency (EEA), 2019. Adaptation challenges and opportunities for the European energy system Building a climate-resilient low-carbon energy system. Available at: https://www.eea.europa.eu/publications/adaptation-in-energy-system/downl oad. Accessed 2 May 2020.

32. Fouzia HB. 2019. Monitoring of Marine Pollution. BoD - Books on Demand.

33. André A., Sundin AM, Linderholm L, 2016. Published by the Swedish Environmental Protection Agency 32.

34. United Nations Development Program, 2000. World Energy Assessment: Energy and the challenge of Sustainability. In World Energy Assessment.

35. Integrated analysis of climate change, land-use, energy and water strategies | Nature Climate Change, 2013. https://www.nature.com/ articles/nclimate1789. Accessed 25 Jan 2021.

36. OECD/IEA, 2015. World Energy Outlook Special Report: Energy and climate change. 2015, IEA Publishing.

37. IRENA, 2017. Rethinking Energy 2017: Accelerating the global energy transition.

38. OECD/IEA and IRENA, 2017. Perspectives for the Energy Transition. 
39. United Nations, 2015. Transforming our world: the 2030 Agenda for Sustainable Development, 2030.

40. Global and regional potential of wastewater as a water, nutrient and energy source - Qadir - 2020 - Natural Resources Forum - Wiley Online Library, 2020. https://doi.org/10.1111/1477-8947.12187.

Publisher's Note Springer Nature remains neutral with regard to jurisdictional claims in published maps and institutional affiliations. 